\title{
La fantástica historia de la increíble prion
}

\author{
The fantastic story of the incredible prion
}

Walter Ledermann D. ${ }^{1}$

${ }^{1}$ Centro de Estudios Humanistas Julio Prado.

\begin{abstract}
Resumen
Desde el scrapie de la oveja a la encefalopatía espongiforme bovina y desde el kuru a la enfermedad de Creutzfeldt-Jakob, tenaces investigadores buscaron los misteriosos agentes de estos desórdenes neurológicos, hasta que Stanley Prusiner descubriera y describiera las priones en los ochenta, obteniendo el Premio Nobel en 1997. Pero, este no fue el final de esta fantástica historia de la increible proteina designada prion por Prusiner, porque ahora, la investigación en neurociencia ha encontrado proteínas prion-like jugando un importante papel en la génesis de la memoria a largo plazo.
\end{abstract}

Palabras clave: prion, encefalopatías espongiformes, memoria a largo plazo.

\section{Encefalopatías espongiformes trasmisibles}

L

a historia comienza hace unos 250 años con el scrapie de las ovejas, la primera de las misteriosas encefalopatías espongiformes trasmisibles (EET), grupo de enfermedades que afectan a varios animales y luego al hombre, caracterizadas por su curso subagudo, su carácter degenerativo e irreversible, y su especial mecanismo de trasmisión, ligado a una enigmática proteína cerebral, descubierta por Staney Prusiner, quien la denominó prion en $1982^{1}$.

En el hombre las EET comprendían principalmente la enfermedad de Creutzfeldt-Jakob (ECJ); la enfermedad de Gertsmann-StrausslerScheinker (EGGS), variante familiar de la anterior; y el kuru, que eran las más famosas, aunque luego veremos cómo otras se han ido agregando a la lista. En los animales, se cuentan hasta ahora el mencionado scrapie ovejuno, la encefalopatía trasmisible del visón, la enfermedad crónica agotadora del alce y de una variedad de ciervo, para terminar con la encefalopatía espongiforme bovina (EEB) o enfermedad de las vacas locas, que despertó la inquietud mundial por el tema en 1986.

\begin{abstract}
From the scrapie of the sheep to the bovine spongiform encephalitis, and from the kuru to the Creutzfeldt-Jakob disease, tenacious investigators searched for the mysterious agent of these neurological disorders, till Stanley Prusiner discovered and described the prion in the eighties, wining the Nobel Prize in 1997. But this was not the end of the fantastic history of the incredible protein designed prion by Prusiner, because now the investigation on neuroscience has founded prion-like proteins playing an important role in the genesis of the long-term memory.
\end{abstract}

Key words: prion, spongiform encephalopaties, long-term memory.

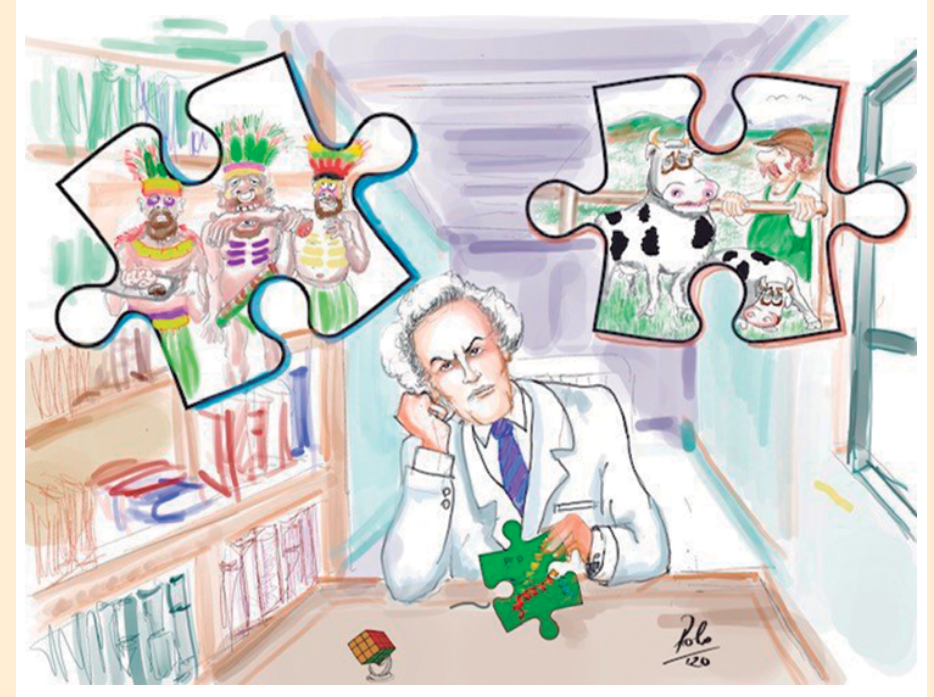

Correspondencia a:

Walter Ledermann Dehnhardt

oncemayor@gmail.com 
En 1936 se estableció que el scrapie (tembladera, rascadera) era una enfermedad transmisible y en 1947 , que podía propagarse a otra especie animal, al aparecer en E.U.A. en criaderos de visones alimentados con productos extraídos de ovejas enfermas ${ }^{2}$. Si alguien hubiera recordado este fenómeno, quizás nunca hubiésemos tenido vacas locas.

\section{Los caníbales de las islas Fore}

En octubre de 1956 encontramos a Vincent Zigas, un típico representante de la investigación aventurera, trabajando como oficial médico en el Departamento de Salud Pública del "Territorio de Papúa y Nueva Guinea", que entonces formaba parte de Australia. Zigas, de ascendencia alemana, mostró ser digno de sus ancestros Koch, Eberth y compañía, interesándose y lanzándose de lleno a la investigación en terreno de una extraña enfermedad que afectaba a unos indígenas en la región de Moke, al interior de las inexploradas Tierras Altas.

Nuestro amigo hablaba estonio, lituano, alemán, ruso, polaco y algún dialecto de la Melanesia, dice una breve reseña suya de autor desconocido. Estudió medicina en las universidades de Kaunas, Koenisberg, Breslau y Hamburgo, para luego emigrar a Australia y de ahí pasó al puesto en que lo encontramos ${ }^{3}$. Resumió su obra en un libro que lleva el curioso título de Laughing Death, que apareció en las librerías luego de su muerte, y que podríamos traducir La muerte que ríe, imitando el título de Víctor Hugo 4 .

Estos indígenas eran los fore, del distrito de Okapa, unas veinte mil personas que vivían talando árboles para traficar con su madera y cazando animales selváticos pequeños para sobrevivir. Se hicieron conocidos en 1956 cuando el explorador australiano W.T. Brown describiera la enfermedad neurológica y degenerativa que los afectaba y que ellos llamaban kuru: "temblor con fiebre y frío". Brown, que era buen observador y mejor escritor, dice: la primera señal de una muerte inminente es que el enfermo muestra flojera muscular, que termina en debilidad general y graves problemas para ponerse en pie; sufre terribles temblores, deja de comer, luego pasa el día acostado, ya no se levanta, hasta que finalmente muere . $^{5}$

Los fore poseían su propio lenguaje y costumbres de la edad de piedra, como la práctica de un canibalismo ritual, durante el cual se comían a sus familiares muertos. Entre ellos la incidencia del kuru era altísima; los síntomas y signos del mal hacían pensar en la enfermedad de Creutzfeldt-Jakob; Zigas y Gajdusek terminarían por relacionar ambas patologías.

¿Y quién era Daniel Carleton Gajdusek, que a los pocos meses de iniciada la investigación por Zigas se uniría al equipo? Era un infectólogo norteamericano, a la vez pediatra y virológo, hombre inquieto y devorado por el bicho de la investigación, que viajó a Australia en 1956 para estudiar los problemas médicos de las comunidades primitivas y, curiosamente no se enteró allí del kuru, del que sólo oyó hablar recién de regreso a su país. De inmediato decidió meterse en la aventura y el 15 de marzo de 1957 escribió a Joseph E. Smadel, Associate Director de los NIH de Bethesda, diciéndole que si su Instituto Mental de Salud tenía la gente más capacitada para estudiar las enfermedades mentales, debería ser el más interesado en esta patología heredo-familiar, que tenía la más alta concentración epidémica jamás vista; y que los genetistas debían subirse a la pelota, pues si una epidemia de enfermedad de ganglio basal estaba presente, ya fuese post encefalitis, tóxica o alérgica, entonces la totalidad de la medicina debería interesarse ${ }^{6}$.

Zigas y Gajdusek llevaron a cabo en pocos meses de 1957 una "minuciosa delimitación de la enfermedad", que afectaba de preferencia a mujeres y a niños, y se caracterizaba por ataxia cerebelosa y temblor progresivos, sobreviniendo la muerte al cabo de un año, con profundo deterioro neurológico, pero sin clara demencia. No pudieron, sin embargo, determinar un factor etiológico preciso o encontrar tratamiento eficaz ${ }^{7,8}$.

Es importante imaginar en qué circunstancias se llevaron a cabo estos estudios, en territorio hostil y entre salvajes que vivían en la edad de piedra. ¡Más no podían hacer! Entonces vino en su ayuda un tercero, Igor Klatzo ${ }^{9}$, quien en una carta fechada el 13 de septiembre de 1957 le cuenta a Gajdusek que había estudiado los cerebros de seis fallecidos por kuru: "Temo ser incapaz de darle algunas guías útiles en cuanto a la etiología de esta enfermedad, que parece definitivamente ser una nueva condición sin ninguna descripción similar en la literatura, siendo la más cercana la que describieran Jakob and Creutzfeldt".

\section{El kuru llega a su fin}

La incidencia era de $1 \%$ de la población, en tanto que $50 \%$ de todas las muertes entre los fore se debían al kuru. El desarrollo del kuru es lento y su período de incubación puede durar hasta 30 años, lo que ocultaba la relación causa-efecto. Si bien todos los pacientes han fallecido al cabo de un año, el desarrollo normal de la enfermedad suele tomar sólo entre tres y seis meses, muriendo la inmensa mayoría de los pacientes en el curso del tercer mes.

Los fore se comían a los muertos no porque tuvieran hambre o fueran naturalmente caníbales, sino a fin de conservar la fuerza vital del fallecido dentro del pueblo, para lo cual los hombres se alimentaban de las manos y los pies del cadáver, en tanto que las mujeres y niños 


\section{La variante joven de la enfermedad de Creutzfeldt-Jacob (ECJ)}

se comían el resto del cuerpo, especialmente el cereb estando por ello más expuestos al contagio, ya que en este órgano residía el agente infeccioso.

Los esfuerzos por terminar con el canibalismo se iniciaron en 1957, concluyendo la práctica en 1985, luego que $10 \%$ del pueblo muriera por su causa. De esta manera llegó la extinción del kuru, aunque pueden aparecer casos tardíos, considerando que el período de incubación puede llegar a décadas. Como dato anecdótico y no confirmado, se sostiene que el kuru se inició entre los fore luego de comerse a un misionero afectado de ECJ, quien se vengó así en forma póstuma de sus asesinos. La similitud entre ECJ y el kuru ya había sido lógicamente planteada en 1959, avalada luego por la posibilidad de trasmitir ambas a monos y $\operatorname{simios}^{10} \mathrm{y}$ por la adquisición accidental de la primera en hombres que recibieron terapia hormonal con hipófisis contaminada ${ }^{11}$.

\section{Enfermedad de las vacas locas}

El primer acto de esta fantástica historia ocurre en 1986, cuarenta años después de ocurrida la epizootia de los visones, cuando se identifica por primera vez la encefalopatía espongiforme bovina (EEB) en el Reino Unido, afectando a más de 155.000 de estos rumiantes, amplificada por la exposición de los terneros, causada por la ingestión de alimentos enriquecidos con carcasas de vaca, aunque también las ovejas pudieron ser la fuente original, al emplearse con el mismo fin parte de sus restos.

El segundo acto se inicia diez años después de la enorme epizootia de las vacas locas, cuando recién el 20 de marzo de 1996, el comité de expertos que asesora al gobierno del Reino Unido, emite un informe que va a desencadenar la matanza de todos los rebaños del país, el bloqueo europeo a la exportación de carne británica y el paso de la EEB a los noticiarios televisivos. Se pudo determinar que esta singular enfermedad vacuna era trasmisible al ser humano, basándose en la aparición de diez casos en adultos jóvenes de una nueva variante de la ECJ, en el período comprendido entre febrero de 1994 y octubre de 1995, al que luego se sumaría otro en un adulto de 26 años.

Cabe preguntarse si estas observaciones justificaban matar a todas las vacas del reino o si fue una precipitación y una grave equivocación. Por otra parte, como la frecuencia de EEB en otros países europeos era escasísima, puede entenderse la dureza del veto que se impuso a los productos británicos, en el comprensible afán de evitar la diseminación del mal. Encontramos razón a quienes culpaban del desastre a la práctica británica de reciclar el ganado fallecido (vacas, cabras y corderos) para alimentar al ganado vivo.
La ECJ fue descrita por Creutzfeldt en 1920, mucho antes del kuru, como un cuadro de demencia progresiva en una joven de 22 años, y al año siguiente por Jakob en cuatro pacientes más viejos. En 1950 se estableció la unidad entre las descripciones de los casos de Creutzfeldt y casos similares descritos por Jakob, naciendo la ECJ. Esta es una enfermedad de gente sobre los 65 años (Creutzfeldt describió justamente la excepción, que es más que rarísima), siempre mortal, con una incidencia mundial estimada en uno por millón. Los casos familiares constituyen entre 10 y $15 \%$. Entre los judíos libaneses, que acostumbran comer ojos y cerebro de cordero, la incidencia de ECJ es 40 veces mayor que entre la población normal, estableciéndose una clara relación con el scrapie ${ }^{13}$.

Habiendo cundido el pánico con la aparición de la variante "joven" del Creutzfeldt-Jakob, se reunió en Ginebra, en abril de 1996, un comité consultor de la Organización Mundial de la Salud para analizar los diez casos presentados a la fecha, encontrando algunas diferencias, tanto clínicas como en anatomía patológica entre la enfermedad original y su variante. En primer lugar, lo que destacaba claramente a la variante era la edad de comienzo, entre los 16 y los 39 años (mediana 28), habiendo fallecido hasta ese momento ocho de ellas, cinco antes de cumplir treinta años. En E.U.A., donde existía un completo programa de vigilancia de la ECJ, eran rarísimas las muertes antes de esta edad, siendo la mediana de muerte los 68 años. Los rasgos clínicos atípicos incluían prominentes cambios de conducta, seguidos luego por anormalidades neurológicas: ataxia dentro de semanas o meses, demencia y, más tardíamente, contracciones musculares ${ }^{14}$.

Con tales antecedentes, este grupo OMS no pudo pronunciarse claramente, concluyendo: No hay una relación definitiva entre la EEB y la variante de ECJ, pero que evidencia circunstancial sugiere que la exposición a EEB puede ser la explicación más aproximada para estos diez casos. Luego vienen las frases vacuas, típicas de estos informes, diciendo que se requieren con urgencia nuevos estudios cientificos sobre la materia.

Viéndolo en su aspecto positivo, este informe entregaba recomendaciones prácticas y categóricas para la prevención de esta patología, recalcando que ningún producto de cualquier animal sospechoso de una EET podía entrar a una cadena alimenticia; que todos los países debían revisar sus métodos de esterilización, para lograr la completa inactivación de los agentes de EET (cualesquiera que ellos fueran); que debía establecerse la adecuada vigilancia epidemiológica; que todos los países debían poner en entredicho el uso de tejidos de rumiantes como alimento de otros rumiantes; que los productos 
medicinales que empleaban material bovino debían ser rigurosamente controlados. Se estableció, otrosí, que la leche era un producto seguro y no trasmitía la EET, al igual que sus derivados y que la gelatina utilizada en la cadena alimentaria.

Antes, entre 1970 y 1989, sólo se registraba un caso de ECJ menor de 30 años en Inglaterra, en tanto que en otros países su incidencia era igualmente rarísima. Nos preguntamos si luego de la epizootia se encontró más porque la EEB hizo poner más atención en la búsqueda o porque mejoró el diagnóstico, como lo reflejaba en que se diagnosticaba también más la ECJ “clásica". En todo caso, la coincidencia era grande: considerando una incubación de cinco a diez años, la gestación de los casos correspondía al período pre-prohibición, al final de la década de los ochentas. Y sigue el comité: la exposición al agente de la EEB es quizás la más plausible explicación de nuestros hallazgos. Sin embargo, enfatizamos que no tenemos evidencia directa de esta relación y que otras explicaciones son posibles.

\section{Prusiner gana el Premio Nobel}

El tercer e hipotético acto de esta historia de las vacas locas pudiera ser la ceremonia en el salón de honor donde el Rey de Suecia entrega el Premio Nobel de Medicina 1997, que ha ganado Stanley Prusiner por el descubrimiento del agente causal de las EET, publicación que el investigador se apresuró en hacer en 1987, un año después del iniciarse el caso de las vacas locas ${ }^{15}$. Al momento de la solemne ceremonia, ya podía el laureado dar una explicación más detallada de la prion, algo así como:

La proteína de la prion fue encontrada en mi laboratorio y al año siguiente su secuencia de aminoácidos fue determinada por Leroy Hood. Con este conocimiento, siguieron estudios de biología molecular, con una explosión de nueva información. Colaboré con Charles Weissmann en la clonación molecular del gen que codifica la proteina prion (PrP) y con George Carlson y David Kingsbury en ligar el gen de la PrP al control del tiempo de incubación del scrapie en ratones. A pesar de la fuerte convicción de muchos, ningún ácido nucleico fue encontrado ${ }^{16}$.

Las enfermedades priónicas pueden presentarse como desórdenes genéticos, infecciosos o esporádicos, todos los cuales involucran modificación de la proteina prion (PrP), una constituyente de células normales de los mamíferos. Las priones están desprovistas de ácido nucleico y parecen estar compuestas exclusivamente de la modificada isoforma de PrP designada PrPSc. La normal, PrP celular, designada como PrP ${ }^{C}$, se convierte en $P_{r P} P^{S c}$ a través de un proceso en que una porción de su estructura helicoidal y de plegamiento sufre una transición estructural, con profundos cambios en las propiedades físico-químicas de la PrP. La secuencia aminoácida de la PrP ${ }^{S c}$ corresponde a la codificada por el gen PrP del huésped mamífero en el cual se replica finalmente. En contraste con los patógenos que tienen un genoma de ácido nucleico que codifica propiedades cepa-especificas en genes, las priones encriptan estas propiedades en la estructura terciaria de la PrPSc. Estudios transgenéticos argumentan que la PrP $P^{S c}$ actúa como una matriz sobre la cual $\operatorname{Pr}^{C}$ se reforma en una naciente molécula de PrPsc a través de un proceso facilitado por otra proteina ${ }^{17}$.

A Prusiner esta explicación le ha parecido clarísima. Nosotros preferimos decir que, en términos simples, la prion es ingerida con la carne de animales infectados $\mathrm{y}$, como es mayormente resistente a la proteasa, no es digerida y sigue hasta introducirse a las células nerviosas de su nuevo huésped, modificando sus proteínas normales "por contagio" para convertirlas en nuevas priones, generando así una reacción en cadena, con aglomeraciones de proteína defectuosa. Finalmente las neuronas se llenan de vacuolas y el cerebro se hace esponjoso.

La verdad es que, a esa altura del Nobel, merced a la aplicación de las recomendaciones de todos los expertos, el problema de las vacas locas había sido controlado, pero el recelo respecto a la carne vacuna inglesa era difícil de erradicar. Aunque en el año 2005 se quiso culpar el origen de este desastre a carne traída de India que incluiría también una parte humana ( $;$ qué morboso film de terror!), la burda calumnia fue pronto desmentida, y el consenso mundial es que la epizootia se inició en el Reino Unido en la forma que aquí se ha contado, tanto así que más de 330.000 vacas infectadas en la Unión Europea hasta el año 2007, el 98,3\% de los casos fueron en dicho país, donde se habría sacrificado por esta causa la escalofriante cifra de dos millones de bovinos ${ }^{18}$.

Cabe entonces preguntarse: ¿enfermedad de las vacas locas o enfermedad de los hombres locos? Por ahora, podemos terminar con las palabras premonitorias de Charles Darwin en 1852: "Cuando el hombre expone, incluso sin intención, sus animales y sus plantas a diversas condiciones de vida, surgen variaciones que no puede impedir ni contener" 19 .

$¡ Y$, ciertamente, nunca las vacas en estado salvaje comieron ovejas!

¿Qué se sabe ahora?

En la actualidad persisten algunos enigmas, aunque existe consenso en varios puntos y se define a las enfermedades producidas por priones como trastornos cerebrales degenerativos y progresivos, letales y sin tratamiento conocido, incluyendo entre las que afectan al hombre, como estrella principal, a la enfermedad de CreutzfeldtJakob (ECJ), con su variante adquirida al comer carne contaminada (vECJ), que fuera descrita como la variante 


\section{Un vuelco espectacular en la historia de la prion}

Cuando Stanley Prusiner descubrió que una proteína alterada causaba las encefalitis espongiformes de animales y hombres, el escepticismo y un disimulado rechazo hicieron presa de los infectólogos: no era un microorganismo, sino apenas una molécula proteica, de modo que no había espacio para antimicrobianos y vacunas; su generación en el cerebro, su transmisión por canibalismo y su incierto mecanismo de contagio "por vecindad", no pertenecían a la infectología tradicional; en fin, todo lo que hacía atractivo el estudio de virus, bacterias y hongos estaba aquí ausente. El interés por la enfermedad de las vacas locas y la variante joven del Creutzfeldt-Jakob pasó y, tras un breve repunte al recibir el Premio Nobel Prusiner en 1997, la curiosa proteína fue olvidada por los infectólogos, entre los que nos incluimos.

Recientemente la lectura de la obra de otro Premio Nobel, el austriaco-estadounidense Eric Kandel, neurobiólogo, nos devolvió el interés al hablarnos de la existencia de una "prion buena", que actúa como mediadora en delicados procesos de nuestra memoria, y emprendimos la tarea de narrar su fantástica historia.

En esta obra para legos, escrita en lenguaje elegante y sencillo a la vez, Kandel define a la prion (agente infecciosa proteica) como: "clase reducida de proteinas infecciosas que pueden adoptar dos formas funcionales distintas: la recesiva, que permanece inactiva o tiene un papel fisiológico ordinario, y la dominante, que se auto perpetúa y es tóxica para las células nerviosas. Los genes que codifican las priones generan la forma recesiva, que por azar puede transformarse en la forma dominante, como ocurre con la ingestión de alimentos que contienen la forma activa. Difieren de otras proteinas por una segunda característica: la forma dominante se perpetúa y hace que la conformación recesiva modifique su forma, se convierta en dominante y también se perpetúe ${ }^{22}$.

La neurociencia aplica el método experimental, estudiando las funciones y procesos mentales como fenómenos biológicos. Kandel, hablando de la formación de la memoria involucra a la CPEB (citoplasmic polyadenylation element-binding protein), proteína de unión al elemento de poliadenilación citoplasmática, que actúa como reguladora de la traducción en la sinapsis, contribuyendo de esta manera a estabilizar la memoria a largo plazo; y a la CREB (cyclic AMP response elementbinding), proteína de unión al elemento de respuesta al AMP cíclico, como reguladora de genes, activada por el monofosfato de adenosina cíclico (AMPC) y la vía de la proteína quinasa $\mathrm{A}$, que así activaría los genes responsables de este tipo de memoria. En suma, para no hundirnos en complicaciones, la CPEB y y la CREB serían vitales en este tipo de memoria. Kandel dice que tanto el activador 
como el represor de la CREB fueron descubiertos por Dusan Bartsch" ${ }^{23}$, mientras Kausik Si "descubrió que estas magnificas moléculas funcionan como priones" 24 . Estas proteínas fueron descritas en la Aplysia, caracol de mar con que Kandel ha trabajado siempre y también se han encontrado en el hipocampo del ratón: dada su estructura priónica, se perpetúan y permiten que la memoria se mantenga por décadas.

La historia la narra vívidamente Kandel en su libro, al maravillarse de cómo podía la memoria persistir largo tiempo, siendo la CPEB, como proteína que era, degradable en pocas horas, perdiéndose con ella el recuerdo: Una hermosa tarde neoyorquina de la primavera de 2001, mientras el sol jugaba con las olas del rio Hudson, estaba yo en mi oficina cuando Kausik entró y me preguntó: ¿Qué me diría si le cuento que la CPEB tiene propiedades similares a los priones? ¡Era una idea insensata! Sin embargo, de ser cierta, podía explicar cómo se mantiene la memoria a largo plazo indefinidamente en la sinapsis, pese a la permanente degradación y renovación de las proteinas. Evidentemente, una proteina que se auto-perpetúa puede mantenerse indefinidamente en las sinapsis, regulando la síntesis local de proteinas necesaria para mantener las nuevas terminales sinápticas. Pronto descubrimos que el paso de la forma inactiva de la CPEB, que no se propaga, a la forma activa (prion), que sí lo hace, está controlado por la serotonina, el trasmisor necesario para convertir la memoria de corto plazo en memoria de largo plazo.

Estimados lectores: gracias a una prion recordamos los bellos días de nuestra infancia, con colores, sonido y olores.

Este descubrimiento fascinante realizado en mi laboratorio -dice Kandel-demuestra que a veces la ciencia básica se parece a una buena novela de misterio en la que surgen elementos inesperados: algún proceso nuevo y sorprendente se oculta en un rincón inexplorado de la vida y se descubre luego que tenía vastos alcances.

Terminamos aquí, mudos... ¿Qué más podríamos decir de esta familia de priones delincuentes, que también tienen su oveja blanca y sin scrapie?

\section{Aclaración}

La Real Academia Española define "prion" como sustantivo masculino:

Del inglés prion, acrónimo de proteinaceous infectious particle (partícula proteínica infecciosa) y -on «-(ón).

1.m. Agente infeccioso, constituido exclusivamente por proteinas, que produce alteraciones neurodegenerativas contagiosas en diversas especies animales.

Esta curiosa asignación de género masculino a una proteína infecciosa, doblemente femenina, mediante la transformación en "agente", es una muestra más del machismo hispanoamericano, que pretendemos combatir, seguramente sin éxito, asignando a esta proteína el género femenino que lógica y lingüistícamente le corresponde. Por otra parte, este "agente" no está "constituido exclusivamente por proteínas”: ES UNA SOLA.

\section{Referencias bibliográficas}

1.- Prusiner S B. Novel proteinaceous infectious particles cause scrapie. Science 1982; 216 (4542): 136-44. doi: 10.1126/ science. 6801762

2.- Ledermann, W. Conducta humana, medio ambiente $y$ patógenos emergentes. Rev Chil Infect 1999; 16 (4): 267-75.

3.- Austlit. "Vincent Zigas: (author/organisation). AustLit. Discover Australian Stories”. www.austlit.edu.au.

4.- Zigas, Vincent (1990). Laughing Death. Clifton, NJ: The Humana Press.

5.- Alonso J R. Universidad de Salamanca. Caníbales, vacas y priones. En: Neurociencia, blog. https://jralonso. es/2011/03/02/historias-de-la-neurociencia-canibales-vacasy-priones/

6.- Holley J D. Carleton Gajdusek; Controversial Scientist. The Washington Post, December 16, 2008; p. B5.

7.- Gajdusek D C, Zigas V. Degenerative disease of the central nervous system in New Guinea. N Engl J Med 1957: 257 (20): 974-8. doi: 10.1056/NEJM195711142572005.

8.- Gadjusek D C, Zigas V. Kuru: Clinical, pathological and epidemiological study of an acute progressive degenerative disease of central nervous system among natives of the eastern highlands of Nueva Guinea. Am J Med 1959; 26: 442-9. doi: 10.1016/0002-9343(59)90251-7.

9.- Spatz M, Hossman K-A. In Memory of Igor Klatzo, 19162007. J Neuropathol Exp Neurol 2008; 67 (2): 170-1. https:// doi.org/10.1097/nen.0b013e318165ae85.

10.- Gadjusek D C, Gibbs C J, Alpers M. Experimental transmission of a kuru-like syndrome to chimpanzees. Nature 1966; 209: 704-9. doi: 10.1038/209794a0.

11.- Brown P. Bovine spongiform encephalopathy and Creuzfeldt-Jakob disease. The link is unproved, but no better explanation is presently forthcoming. Br Med J 1996; 312 : 790-1. doi: 10.1136/bmj.322.7290.841.

12.- Diringer H. Proposed link between transmissible spongiform encephalopathies of man and animals. Lancet 1995; 346: 1208-10. doi: 10.1016/s0140-6736(95)92905-3.

13.- Will R G, Ironside J W, Zeibler M, Cousens S N, Estibeiro $\mathrm{K}$, Alperovitch A, et al. A new variant of Creutzfeldt Jakob Disease in the UK. Lancet 1996; 347: 921-5. doi: 10.1016/ s0140-6736(96)91412-9.

14.- Prusiner S P. Prions and neurovegetative diseases. N Engl J Med 1987; 317: 1571-81. doi: 10.1056/ NEJM198712173172505.

15.- Stanley B. Prusiner. Biographical. NobelPrize.org. Nobel Media AB 2019. https://www.nobelprize.org/prizes/ medicine/1997/prusiner/biographical/ (También en: The Nobel Prizes 1997, Editor Tore Frängsmyr, [Nobel Foundation], Stockholm, 1998).

16.- Prusiner S. Prions. Proc Natl Acad Sci U S A. 1998; 9 5(23): 13363-83. doi: 10.1073/pnas.95.23.13363

17.- https://web.archive.org/web/20100911113104/http://www. eeb.es/pags/europa.htlm. 
18.- Darwin C. El origen de las especies por medio de la selección natural, Bruguera S.A., Barcelona 1967; p. 20.

19.- Gambetti P, Kong Q, Zou W, Parchi P, Chen S G. Sporadic and familial CJD: Classification and characterization. $\mathrm{Br}$ Med Bull 2003; 66 (1): 213-39. doi: 10.1093/bmb/66.1.213.

20.- Benestad S L, Mitchell G, Simmons M, Ytrehus B, Vikøren T. First case of chronic wasting disease in Europe in a Norwegian free-ranging reindeer. Vet Res 2016; 47 (1): 88. doi: 10.1186/s13567-016-0375-4.

21.- Kandel E R. En busca de la memoria. El nacimiento de una nueva ciencia de la mente. Katz Editores, $5^{\text {a }}$ Ed. Buenos

Aires 2013.

22.- Bartsch D, Casadio A, Karl K A, Merodio P, Kandel E R. CREB-1 encodes a nuclear activator, a repressor and a cytoplasmic modulater that form a regulatory unit critical for long-term facilitation. Cell 1998; 95: 211-23. doi: 10.1016/ s0092-8674(00)81752-3.

23.- Si K, Lindquist $\mathrm{S}$, Kandel E R. A neuronal isoform of the Aplysia CPEB has prion-like properties. Cell 2003; 115: 879-91. doi: 10.1016/s0092-8674(03)01020-1. 